\title{
'SPA440' (Nicola) Apple
}

\section{C.R. Hampson, ${ }^{1}$ R.A. MacDonald, D.-L. McKenzie, H.A. Quamme, ${ }^{2}$ and W.D. Lane \\ Agriculture and Agri-Food Canada, Pacific Agri-Food Research Centre, P.O. Box 5000, Summerland, B.C. Canada V0H $1 Z 0$}

Additional index words. cultivar description, fruit breeding, Malus $\times$ domestica

'SPA440' (Nicola) is an attractive, largefruited late-harvest apple with sweet, crisp, juicy flesh. It has a yellow ground color and red blush over color covering about $85 \%$ of the fruit skin (Fig. 1). 'SPA440' has better storage quality and shelf life than most other bicolored apples in the Summerland collection. It retains good texture and juiciness for at least 5 months in air storage at $1{ }^{\circ} \mathrm{C}$, and has excellent shelf life. 'SPA440' blooms very late in the apple blossom season, after 'Fuji' or 'Gala'. The tree is productive and regular bearing, with $90^{\circ}$ branch angles and spreading growth habit. It is not subject to preharvest drop.

Trademark protection is being sought for the name Nicola. The district around Summerland, B.C., was once known as N'kwala's Prairie, in honor of Chief N'kwala who held the property. N'kwala's name was frequently anglicized as Nicola.

\section{Origin}

'SPA440' resulted from a 1981 cross between 'Splendour' and 'Gala' made by W.D. Lane and R.A. MacDonald at the Pacific AgriFood Research Centre (PARC), Summerland, B.C. (Fig. 2). Seedlings were budded in place onto M.26 rootstock in the field in 1984. The seedling was first selected on the basis of its fruit quality and growth habit in 1988, and assigned the breeder's number 8S-26-10. It was propagated for second test beginning in 1989, and evaluated from the time of first cropping for fruit size, sensory traits, storage quality, and bearing habit over 10 years with consistent results. Yield records were only taken from trees propagated on M.9 planted in 1998. In 1996, the selection was advanced to elite-stage testing by H.A. Quamme under the name SPA 440. Controlled trials under test agreements have been established in British Columbia and at selected research sites.

\section{Description}

The following description of the flowers, fruit, tree and leaves uses color designations of the Royal Horticultural Society of London color

Received for publication 4 July 2005. Accepted for publication 3 Aug. 2005. We thank Warren Walters, Mark Neufield, Keith Johnstone, the PARC farm crew, volunteer taste panelists, and staff of the okanagan Plant Improvement Company for ongoing assistance. We also thank Karen Bedford and Tom $\mathrm{Li}$ for reviewing the manuscript.

${ }^{1}$ To whom correspondence should be addressed; e-mail hampsonc@agr.gc.ca.

${ }^{2}$ Retired. chart (1966). Measurements are the average of 10 plant parts unless otherwise specified.

\section{Flower}

Flowering season. Blooms late in season, after 'Fuji', 'Gala' or 'Granny Smith'.

Petal color. Unopened bud is RHS $61 \mathrm{C} / 155 \mathrm{D}$. At bloom, color on upper side is $61 \mathrm{C} / 155 \mathrm{D}$, on lower side is $61 \mathrm{~B} / 155 \mathrm{D}$.

Size. Corolla diameter at anthesis is $56 \mathrm{~mm}$. Petals are cupped. King bloom petals average $18 \times 28 \mathrm{~mm}$, including claw (mean of 20 petals from 10 flowers).

Pollen. The pollen is fertile and has been used successfully in crosses.

\section{Fruit}

Shape. The fruit is globose to globose conical, weakly ribbed, and symmetrical.

Size. Fruit size is large, similar to 'Fuji'. Seventeen harvest-time weights of 10 -fruit samples over 8 harvest years averaged $269 \mathrm{~g}$.

Color. Ground color at maturity is $11 \mathrm{~B}$, covered with about $85 \%$ red (185A). The

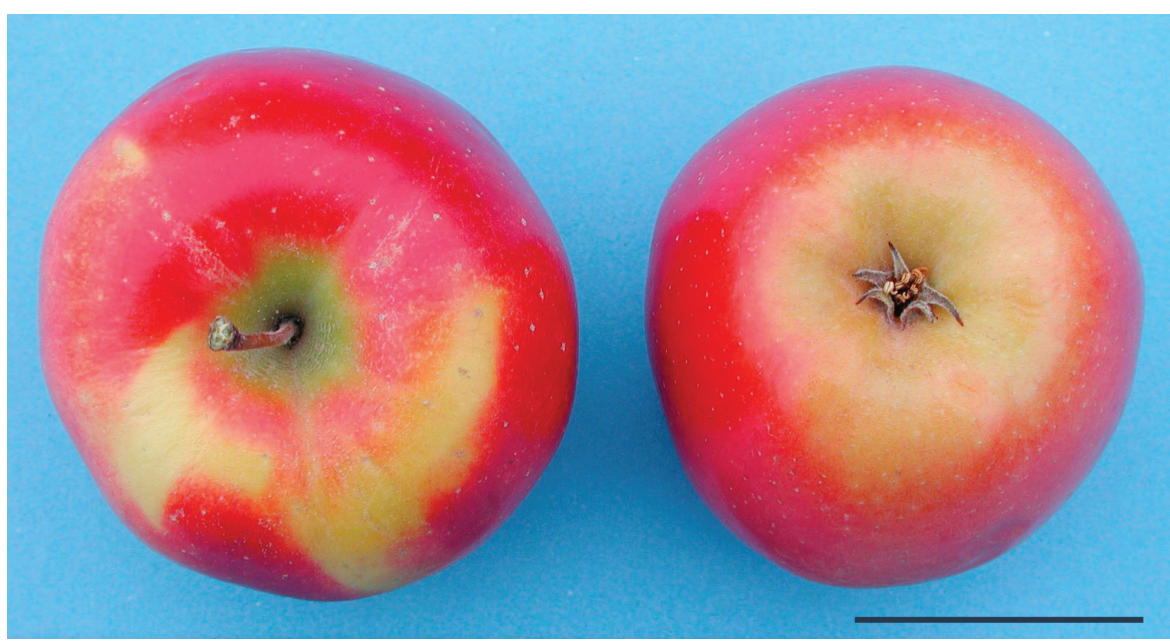

Fig. 1. Fruit of 'SPA440' (Nicola). The scale bar represents $5 \mathrm{~cm}$.

Splendour

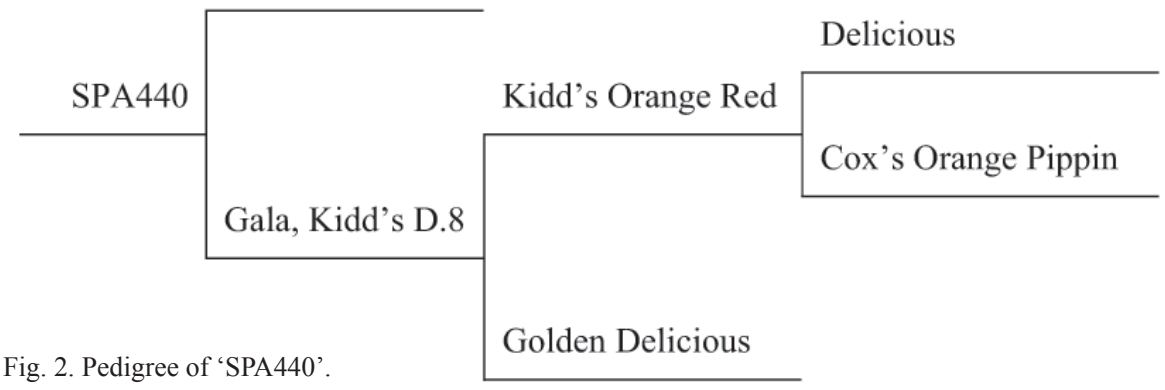

pattern of over color is blush, with faint short narrow streaks. Flesh color is cream to light yellow, 11D.

Skin. The skin is medium in thickness, smooth and glossy. The incidence of russet is very low $(2 \%)$ on cheeks and lenticels, but characteristically present in stem bowl. Russet is more severe in cool humid growing conditions. Lenticels are conspicuous, numerous, medium in size, white or pale tan.

Pedicel. The fruit stem is long, thin, and deeply inserted in the stem bowl. Its length is $39 \mathrm{~mm}$, with thickness $2 \mathrm{~mm}$. Stems frequently break instead of detaching at the spur when the fruit is picked.

Calyx. Sepals are persistent, dry, overlapping, recurved. The eye is closed to half open.

Core. The core is in median position, small, and has closed locules. The inner surface of the locule is smooth or slightly tufted. Seeds are non-tufted, acuminate, and dark brown at maturity.

Texture. The fruitflesh is juicy, firm and crisp, and slightly coarse. The cut flesh will brown.

Firmness at harvest. Flesh firmness at harvest averaged $7.4 \mathrm{~kg} / \mathrm{f}$ over 9 years, as measured by penetrometer using an 11.25 $\mathrm{mm}$ probe.

Soluble solids. At harvest, soluble solids averaged $15.4 \%$ over 9 years, or $15.9 \%$ after 6 to 8 weeks of air storage.

Acidity at harvest. Acidity of the juiced flesh at harvest averaged $0.7 \%$ as malic acid over 9 years.

Flavor. The flesh tastes somewhat starchy and faintly astringent at harvest; it requires 4 


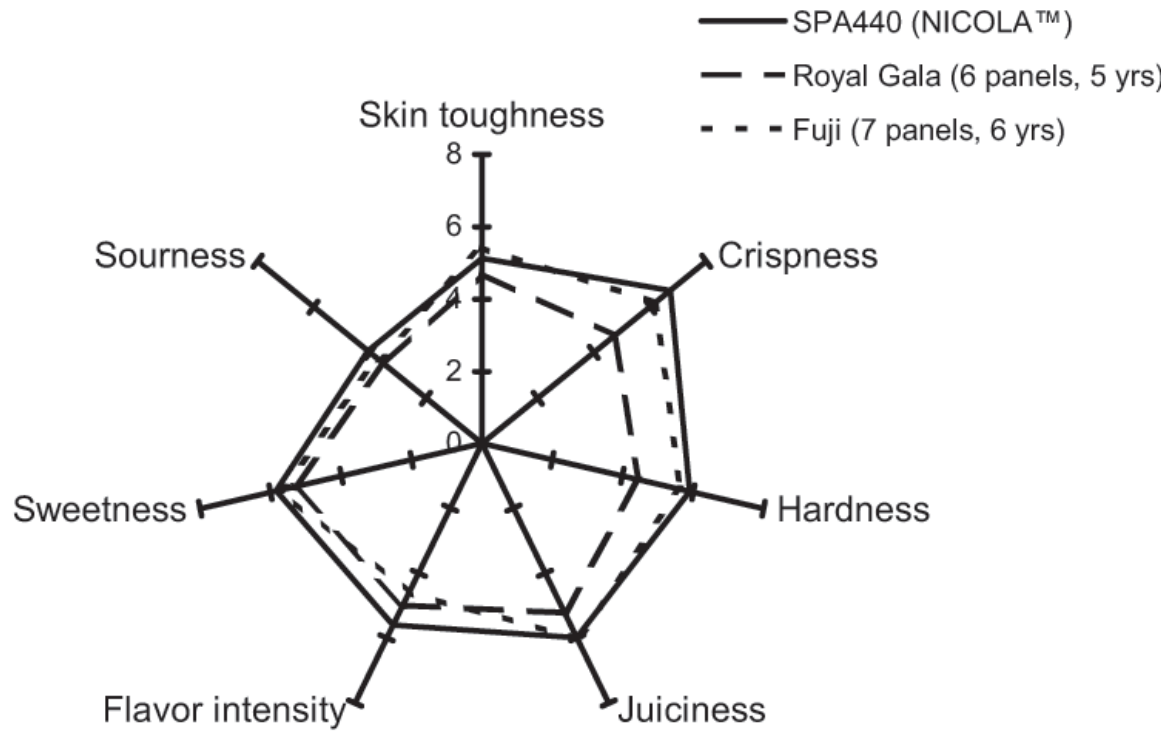

Fig. 3. Intensity of selected attributes, each rated on a 0 (low) to 9 (high) scale, of 'SPA440' fruit relative to commercial cultivars. Twelve trained judges drawn from a larger pool rated the fruit in each panel. The values are means weighted inversely to the error mean square of the analysis of variance for that taste panel. The number of panels and years that the commercial cultivar was tested with 'SPA440' appears in parentheses.

to 6 weeks of cold air storage to develop flavor, when it tastes sweet, aromatic and refreshing. The astringency dissipates in storage.

Maturity season. In Summerland, the first pick of fruit is 11 to 15 Oct., slightly before 'Fuji' and well after 'Delicious' or 'Spartan'. 'SPA440' requires two picks, the second about $5 \mathrm{~d}$ after the first.

Keeping quality and sensory attributes. Fruit of 'SPA440' has a long air storage life of $\geq 5$ months at $1{ }^{\circ} \mathrm{C}$ and good shelf life after storage. Blind hedonic sensory evaluations were run between 49 and $68 \mathrm{~d}$ after harvest, according to Hampson et al. (2000), over 6 harvest years using commercial cultivars as standards. In these tests, the texture and flavor of Nicola were liked more than those of 'Fuji' or 'Royal Gala'. In appearance it scored higher than 'Fuji' but lower than 'Royal Gala'. In separate blind panels, 12 trained judges evaluated the degree or intensity of various attributes (Fig. 3) relative to standards. Attribute intensity was rated between 56 and 90 $\mathrm{d}$ after harvest of Nicola, depending on the year. Skin toughness was intermediate between 'Royal Gala' and 'Fuji' (Fig. 3). Nicola was rated as crisper, harder, more flavorful, sweeter and more sour than either standard (based on $t$ tests, $5 \%$ error level). Juiciness was rated as similar to 'Fuji' and higher than 'Gala'. Nicola retains texture and eating quality at least 5 months at $1{ }^{\circ} \mathrm{C}$, and the skin does not become greasy. Shelf life was tested by removing fruit from air storage, leaving it at $20^{\circ} \mathrm{C}$ for one week, measuring firmness, then subjecting the fruit to hedonic sensory panels as previously described (Hampson et al., 2000). The appearance, texture and flavor of Nicola were rated significantly higher than 'Fuji' (5 years of tests) or 'Delicious' (4 years of tests) in these tests. The loss of flesh firmness over the $7 \mathrm{~d}$ at 20 ${ }^{\circ} \mathrm{C}$ was negligible (average $<0.05 \mathrm{~kg} / \mathrm{f}$ ), with firmness on Day 7 averaging $7.3 \mathrm{~kg} / \mathrm{f}$ in tests run over five harvest years.
Use. 'SPA440' is suitable for use as a dessert apple, and is appropriate for medium- to long-term storage.

\section{Tree}

Vigor. The trees are moderately vigorous. Mean trunk girth on M.9 rootstock $(\mathrm{n}=8)$ seven years after planting was $17.0 \pm 1.1 \mathrm{~cm}^{2}$ (mean \pm SE) for 'SPA440', similar to nearby trees of 'Fuji' $\left(18.9 \pm 1.8 \mathrm{~cm}^{2}\right)$ and 'Spartan' $(14.3 \pm 0.8$ $\mathrm{cm}^{2}$ ). Observations suggest it is less vigorous than 'Gala'. ing.

Shape. The crown is rounded and spread-

Bearing habit. 'SPA440' bears chiefly on spurs and short shoots. It has some bare wood. The trees are regular bearing if thinned, have negligible preharvest fruit drop and good precocity.

Branch angle. Branch angles are mostly near $90^{\circ}$

Productivity. The productivity of trees on M.9 is slightly less than 'Fuji', but with similar yield efficiency. Seven years after planting, the cumulative yield was $68.8 \pm 3.6 \mathrm{~kg} /$ tree for 'SPA440', $79.9 \pm 5.1$ for 'Fuji' and $36.1 \pm 1.4$ for 'Spartan' $(\mathrm{n}=8)$. These figures exclude dropped fruit, which was significant only for 'Spartan'. Cumulative yield efficiencies (in $\mathrm{kg} \cdot \mathrm{cm}^{-2}$ trunk girth) for 'SPA440', 'Fuji' and 'Spartan' were respectively $4.1 \pm 0.2,4.3 \pm 0.2$ and $2.6 \pm 0.1$ after 5 cropping years (mean $\pm \mathrm{SE}$ ). The 'Fuji' trees in this plot were not biennial-bearing.

Thinning. 'SPA440' requires moderate to heavy thinning but is less prone to oversetting than sister cultivar '8S6923' (Aurora Golden Gala). Thin to single king fruit 15 to $20 \mathrm{~cm}$ apart.

Branch appearance. The bark on one yearold dormant shoots is purple-brown (RHS 183A). The upper half of dormant 1-year-old shoots has weak whitish pubescence; lenticels are white, small to medium sized, medium to high in density, and conspicuous. On older shoots, lenticels are rougher and sometimes raised, oval to round, and become more corky with age.

Hardiness. Early winter (late November) hardiness of 1-year old twigs was assessed in controlled freeze tests in a single year, according to procedures previously published (Quamme, 1976). 'SPA440' was similar to 'Golden Delicious' and significantly less hardy than 'Spartan', so was rated as moderately winter tender.

Disease resistance. The disease resistance of 'SPA440' is comparable to its parents. It is susceptible to apple scab [caused by Venturia inaequalis (Cke.) Wint.]. Powdery mildew [caused by Podosphaera leucotricha (Ell. \& Ev.) Salm.] incidence was low under conventional management at PARC. No natural outbreaks of fire blight [incited by Erwinia amylovora (Burr.) Winslow] affected 'SPA440' during its 20 years in the fields at PARC. Deliberate inoculations with fire blight bacteria in the field and greenhouse have yielded conflicting results, and further work is needed to characterize its resistance level.

\section{Leaves}

Size. Leaf blades average $66 \times 109 \mathrm{~mm}$ in size with a length: width ratio of 1.7 .

Petiole. Petioles are $34 \mathrm{~mm}$ long on average.

Margins and tips. The leafapex is acuminate to cuspidate, and the margins are serrate.

Color. The adaxial side is 147A and glossy; anthocyanin coloration of veins is medium to strong.

\section{Cultural Notes}

'SPA440' sets well and must be thinned, but is less prone to oversetting than its sibling '8S6923' (Aurora Golden Gala). If grown on the superspindle system, the trees should not be cropped heavily until they reach their desired height.

Some stem end russet is characteristic but it does not normally break over the shoulders of the fruit. The exception is first-year fruit, where russet may be so severe as to make the fruit unsaleable. 'SPA440' has not yet been tested in eastern North America, but caution is urged in view of the performance of its sibling selection $8 \mathrm{~S}-26-50$, which is prone to severe russet in some eastern test sites in the NE-183 Apple Cultivar Evaluation trials.

The cultivar requires two picks, the second about $5 \mathrm{~d}$ after the first. Fruit is ready to harvest when the ground color breaks from green to yellow and flavor development begins. In Summerland, the starch index at this stage is 3 to 4 on the Cornell generic chart (Blanpied and Silsby, 1992). Some stem end splits can occur if the fruit is fully mature or overmature. The first harvest date of 'SPA440' is 7 to $10 \mathrm{~d}$ before 'Fuji' in Summerland. The fruit needs 4 to 6 weeks of storage for proper flavor development, and can be stored successfully for up to 5 months in air at $1{ }^{\circ} \mathrm{C}$ without losing good texture. Thereafter texture remains good for some time, but a flat flavor develops due to loss of acidity. No controlled-atmosphere storage data are available. 
No significant postharvest disorders or problems have been encountered to date. The fruit is not subject to superficial scald, bitter pit, internal browning or off-flavor development in storage. The stems are long but flexible, and stem punctures have not been a problem in our trials.

\section{Availability}

Re-propagations of 'SPA440' were tested at the Centre for Plant Health in Sidney, B.C., using woody and herbaceous host bioindicators, as well as serological and molecular methods. Infection with chlorotic leaf spot and apple stem pitting viruses was detected. 'SPA440' underwent successful heat therapy and certified propagation wood is now available. 'SPA440' is being protected in Canada (PBR application no. 05-4782), the European Community and the United States (USPP pending). Commercialization rights have been granted to the okanagan Plant Improvement Company (PICO, Box 6000, Summerland, BC, Canada, V0H 1Z0). Information on the availability of propagation wood, and inquiries regarding licensing or acquisition of trees outside of Canada should be addressed to PICO. Trademark protection is being sought for the name Nicola.

\section{Literature Cited}

Blanpied, G.D. and K.J. Silsby. 1992. Predicting harvest date windows for apples. Cornell Coop. Ext., Geneva, N.Y., Info. Bul. 221.

Hampson, C.R., H.A. Quamme, J.W. Hall, R.A. MacDonald, M.C. King, and M.A. Cliff. 2000. Sensory evaluation as a selection tool in apple breeding. Euphytica 111:79-90.

Quamme, H.A. 1976. Relationship of the low temperature exotherm to apple and pear production in North America. Can. J. Plant Sci. 56:493-500.

Royal Horticultural Society. 1966. Royal Horticultural Society colour chart. Royal Hort. Soc., London. 